\title{
Orofacial Dysfunction In Cleft And Non-Cleft Patients Using Nordic Orofacial Test - A Screening Study
}

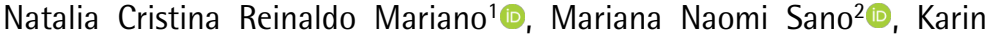 \\ Hermana Neppelenbroek ${ }^{\circledR}$, Ana Lúcia Pompéia Fraga de Almeida1,3, \\ Thais Marchini Oliveira ${ }^{1,4}{ }^{-}$, Simone Soares ${ }^{1,3}$
}

\begin{abstract}
Cleft lip, alveolus and palate is a congenital malformation caused by the lack of fusion of the lip and palate embryonic processes, which may disrupt the main functions of the stomatognathic system. Aim: This study aimed to assess the orofacial dysfunction in individuals with cleft lip, alveolus, and palate compared to non-cleft patients. One hundred and twenty individuals between 32 and 65 years of age were selected in the Craniofacial Center and in the School of Dentistry and divided into two groups: noncleft patients (N-CLAP) and cleft lip, alveolus, and palate patients (CLAP). The two groups were matched by gender. Each individual was interviewed and submitted to a clinical evaluation during which the NOT-S was used to assess orofacial dysfunction. To verify the intra-examiner agreement, the values were compared using the Kappa test. The Mann-Whitney test compared performance on the NOT-S between the groups. The Chi-Square test compared the NOT-S domains between the groups. A comparison of the NOT-S scores between the groups revealed statistically significant differences in gender $(p<0.001)$, but no statistically significant differences in the intragroup gender comparison were found. The assessment of the NOT-S domains between the N-CLAP and CLAP groups exhibited statistically significant differences in domains: breathing $(p=0.021)$, chewing and swallowing $(p<0.001)$, and dryness of the mouth $(p=0.002)$ of the interview and significant differences in all domains of the clinical examination $(p<0.001)$. Individuals with CLAP showed more orofacial dysfunction than non-cleft patients, without gender differences, after being assessed through the NOT-S.
\end{abstract}

\author{
'Hospital for Rehabilitation \\ of Craniofacial Anomalies, \\ USP - Universidade de São \\ Paulo, Bauru, SP, Brazil \\ ${ }^{2}$ Bauru School of Dentistry, \\ USP - Universidade de São \\ Paulo, Bauru, SP, Brazil \\ ${ }^{3}$ Department of Prosthodontics \\ and Periodontology, Bauru School \\ of Dentistry, USP - Universidade \\ de São Paulo, Bauru, SP, Brazil \\ ${ }^{4}$ Department of Pediatric \\ Dentistry, Orthodontics and \\ Public Health, Bauru School of \\ Dentistry, USP - Universidade de \\ São Paulo, Bauru, SP, Brazil
}

Correspondence: Simone Soares, Alameda Dr. Octávio Pinheiro Brisolla, 9-75, 17012-901 Bauru, SP, Brasil. Tel: +55-14-32358312. e-mail: sisoares@usp.br

Key Words: cleft palate, craniofacial anomalies, mastication, orofacial cleft(s), swallowing.

\section{Introduction}

The stomatognathic system is controlled by the central nervous and neuromuscular systems and coordinates breathing, swallowing, sucking, mastication, and speech through the actions performed by hard structures (bones, teeth), elastic soft tissues (arteries, veins, and nerves), and dynamic soft tissues (lips, tongue, cheeks, and glands) (1). These integrated activities of the central nervous and neuromuscular systems result in orofacial function. Any genetic, congenital, anatomic, or functional alteration caused by disease or trauma may lead to an instability or change in the stomatognathic system and may alter these functions (1).

Human embryonic facial development is a very complex event. A single genetic alteration can result in anomalies ranging from small asymmetries to large facial defects with aesthetic and functional consequences. Cleft lip and palate $(2,3)$ is a congenital malformation caused by the lack of fusion of the lip and palate embryonic processes, which may disrupt the main functions of the stomatognathic system (4). Severe sequelae, such as hearing loss (5), speech problems (6), nutritional deficits (7), and low self-esteem due to bullying (8), may occur due to the lack of proper treatment.

Orofacial dysfunction, which can range from a simple alteration in the individual's facial symmetry to more complex changes in swallowing, speech, and masticatory muscles, with alteration in the facial pattern, can incapacitate an individual, both aesthetically and functionally $(9,10)$. To assess orofacial dysfunction, the Nordic Orofacial Test-Screening (NOT-S) quantifies orofacial dysfunction through a structured interview and clinical examination (1). To evaluate the orofacial dysfunction of patients with cleft lip, alveolus, and palate after the rehabilitation treatment, and prior to patient discharge from Craniofacial Center, it is important to verify whether the results obtained by the multidisciplinary treatment reach the proposed objectives and enable the insertion of patients in society.

Previous studies (11-13) have shown that cleft lip and palate affects the quality of life of these individuals. A recent study (14) on Health-Related Quality of Life and Oral-Health Related Quality of Life in adults with cleft lip, alveolus, and palate (CLAP) suggests the need for 
interdisciplinary approaches to improve CLAP management and intersectoral actions to reduce the impact of social inequalities.

To the best of our knowledge, there is a paucity of literature on orofacial dysfunction of individuals with CLAP after rehabilitation. Therefore, this study aimed to assess the orofacial dysfunction in individuals with cleft lip, alveolus and palate compared to non-cleft patients. The hypothesis to be studied states that patients with cleft present higher orofacial dysfunction than non-cleft patients.

\section{Material and Methods}

\section{Study Design}

This observational cross-sectional study was approved by the Institutional Review Board under protocol no. 01924012.6 .0000 .5441 and is in accordance with the STROBE guidelines.

\section{Setting}

The age range selected for this study was based on the patients with CLAP who had already completed treatment at the institution and were involved with routine care for dental prostheses. All individuals with and without \& CLAP were recruited by a trained and calibrated examiner (Doctor of Dental Science - Master's degree student) in the Craniofacial Center for the treatment of CLAP and in the clinics of a School of Dentistry, respectively. From December 2015 to April 2016, the individuals were selected and matched based on gender and then underwent a clinical examination and completed the questionnaire both at the Craniofacial Center and in the clinics of the School of Dentistry.

\section{Participants}

The inclusion criteria included individuals with and without CLAP who were aged between 32 and 65 years, and they were matched by gender. Exclusion criteria included individuals with articular degenerative diseases, systemic diseases, severe psychiatric problems and neurological and motor disorders, or a history of hormonal problems and head and neck cancer; smokers; individuals who underwent or were undergoing radiotherapy; individuals with the flu, a cold, or allergic rhinitis; individuals using drugs that may directly or indirectly impair facial muscle activity, individuals using drugs that depress the central nervous system and the presence of systemic disturbances.

All individuals who were treated at the Craniofacial Center underwent the cheiloplasty at three months using Millard's technique and palatoplasty at 12 months using von Langenback's technique. The healing retraction used in these surgeries links the discontinued tissue, but it causes sequelae such as anteroposterior and transverse maxilla development restriction (15).

\section{Determination of the Groups}

One hundred and twenty individuals were divided into two groups:

Cleft Lip, Alveolus, and Palate Group (CLAP): Individuals with complete unilateral and bilateral cleft lip, alveolus, and palate: $n=60$, matched by gender.

Non-Cleft Group (N-CLAP): Individuals without CLAP: $\mathrm{n}=60$, matched by gender.

To avoid bias, in the CLAP group, individuals with unilateral or bilateral CLAP were also matched by the number of cleft types.

\section{Assessment of Orofacial Function}

To evaluate orofacial dysfunction, The Nordic Orofacial Test - Screening (NOT-S) was used. The NOT-S was developed by a committee held in the Second Nordic Conference on Orofacial Therapy in Gothenburg in 2002 to assess orofacial function. It was then translated, culturally adapted, and validated in Portuguese $(1,16)$. The rate of intra-examiner agreement was $97.8 \%$ (test/retest), and the Brazilian version of the NOT-S was considered to be validated $(1,16)$.

The NOT-S comprises a structured interview and a clinical examination (Table 1). The interview was performed by reading the questions contained in the questionnaire for each domain. One examiner previously calibrated and performed the interview and the clinical examination (Doctor of Dental Science and Master's degree student). Each domain has one to five items, which matches the complexity of the evaluated function. The interviewer marked "yes" if the answer to one of the questions or the performance of one of the items contained criteria indicating an impaired function. Each domain is scored 0 or 1 . The domain is scored 0 if no item is marked "yes". The presence of at least one "yes" in a domain is scored 1 , indicating a dysfunction in that domain. The NOT-S total score ranges from 0 to 12. The greater the NOT-S score, the greater the orofacial dysfunction.

Table 1. Nordic Orofacial Test-Screening (NOT-S) domains

\begin{tabular}{lccc}
\hline & NOT-S Interview & & NOT-S Examination \\
\hline I & Sensory Function & 1 & Face at rest \\
II & Breathing & 2 & Nose breathing \\
III & Habits & 3 & Facial expression \\
IV & Chewing and swallowing & 4 & $\begin{array}{c}\text { Masticatory muscle } \\
\text { and jaw function }\end{array}$ \\
V & Drooling & 5 & Oral motor function \\
VI & Dryness of the mouth & 6 & Speech \\
\hline
\end{tabular}




\section{Sample Size Calculation}

The sample size was calculated according to Asten et al. (17), with level of significance of $5 \%$, power test of $80 \%$, p1 estimate of $77 \%$, and $p 2$ estimate of $98 \%$. The minimum sample size was 38 individuals per group.

\section{Statistical Analysis}

To verify the intra-examiner agreement, the same examiner reassessed $10 \%$ of the total sample two weeks after the first assessment, and the values were compared using the Kappa test. Mean and standard deviation values are included in the statistical analysis. The Mann-Whitney test was applied to verify the intra- and intergroup comparison of the NOT-S (dependent variable) performance based on gender (independent variable). The Chi-square test was applied to compare the NOT-S domains between groups (independent variables). A 5\% level of significance was adopted for all statistical tests.

\section{Results}

This study evaluated 85 individuals in the CLAP group. Based on the inclusion and exclusion criteria, 25 individuals were excluded. In the N-CLAP group, 60 individuals were selected and all participated in the study. The total sample was composed of 120 participants. The intra-examiner agreement index was $\mathrm{K}=0.75$.

To avoid bias, in the CLAP group, individuals with different cleft types (unilateral and bilateral) were matched based on gender and group. The intragroup comparison revealed no statistically significant differences between the different cleft types (Chi-square test), so the unilateral and bilateral CLAP individuals were grouped and analysed together.

The mean NOT-S scores were compared between genders and between N-CLAP and CLAP groups. The intragroup comparison of the NOT-S scores revealed no significant differences regarding gender for both groups, N-CLAP female: 0.57 and male: 0.70 and CLAP female: 4.70 and male: 5.30 (Mann-Whitney test). The intergroup comparison of the NOT-S scores showed statistically significant differences between the N-CLAP and CLAP groups for females ( 0.57 and 4.70 , respectively) and males ( 0.70 and 5.30 , respectively).

Table 2 displays the mean and standard deviation values

Table 2. Descriptive analysis of the sample distribution

\begin{tabular}{ccccccccc}
\hline & & $\mathrm{n}$ & Mean & SD & Range & Minimum & Maximum & Median \\
\hline \multirow{2}{*}{ N-CLAP } & Age & 60 & 49.48 & 8.47 & 30.00 & 35 & 65 & 49.50 \\
& NOT-S & 60 & 0.63 & 0.96 & 3.00 & 0.00 & 3.00 & 0.00 \\
\multirow{2}{*}{ CLAP } & Age & 60 & 41.25 & 6.72 & 26.00 & 32 & 61 & 40,00 \\
& NOT-S & 60 & 5.00 & 2.23 & 8.00 & 2.00 & 10.0 & 5.00 \\
\hline
\end{tabular}

of the evaluated variables: gender, age, and NOT-S domains for both groups. The NOT-S scores ranged from 0 to 12 . The orofacial dysfunction was seen in absolute values between N-CLAP (0.63) and CLAP groups (5.00) (Table 2). The most compromised function and the most frequent domains in the N-CLAP group were breathing (II - 24.9\%) and habits (III - 18.3\%). In the N-CLAP group, all domains of the clinical examination were scored zero (0). In the CLAP group, the most frequent interview domains were chewing and swallowing (IV - 59.9\%), breathing (II - 44.9\%), and habits (III - 36.4\%), while the most frequent clinical examination domains were facial expression ( $3-74.8 \%)$, face at rest (1 - 66.6\%), speech (6 - 49.9\%), and masticatory muscle/jaw function (4 - 41.5\%) (Fig. 1). The intergroup comparison revealed statistically significant differences in interview domains II ( $p=0.021)$, IV ( $p<0.001)$, and VI $(p=0.002)$, as well as in all clinical examination domains $(p<0.001)$ (Chisquare test) revealing that in the CLAP group the orofacial dysfunction is more prevalent even after the ending of the treatment by multidisciplinary team.

\section{Discussion}

Orofacial dysfunction is seen in individuals with Parkinson's disease (18), cerebral palsy (10), ectodermal dysplasia (19), Prader-Willi syndrome (20), and Treacher Collins syndrome (21). However, there is a lack of studies in the literature on orofacial dysfunction in CLAP individuals, which makes it difficult to compare our results with others.

The hypothesis was accepted because individuals with CLAP presented more orofacial dysfunction than the N-CLAP group, based on NOT-S questionnaire. The mean NOT-S score of the CLAP group was $5.00 \pm 2.23$. The mean value found in the present study for the N-CLAP participants was $0.63 \pm 0.96$, which is similar to other findings in the literature: $0.4 \pm 0.6$ (1), $0.7 \pm 0.0$ (18), $0.3 \pm 0.5$ (20), and $1.8 \pm 1.4$ (22). These results emphasize the higher values of orofacial dysfunction in individuals with CLAP.

In the CLAP group, the NOT-S interview revealed the following order of occurrence: chewing and swallowing (IV - 60.0\%) and breathing (II - 45.0\%). For the N-CLAP group, breathing (II - 23.3\%) was the most prevalent domain, followed by habits (III - 21.7\%). These data are similar to those reported by Bergendal et al. (9). In the study of Bakke et al. (1), for the group of individuals with congenital malformation and chromosomal abnormality $(\mathrm{n}=28)$, domain IV (53.6\%) was the most prevalent. Similarly, these domains were also the most prevalent in individuals with ectodermal dysplasia (19). On the other hand, Lundeborg et 
al. (23) evaluated oral motor dysfunction in children with adenotonsillar hypertrophy and found the most prevalent domain to be breathing. We expected that domains IV and II would be the most prevalent in CLAP individuals, as the cleft itself causes the communication between the mouth and nose, compromising the occlusal relationship and the maxillomandibular growth, consequently affecting breathing $(24,25)$. Alterations in chewing and swallowing should be carefully evaluated because this present study did not verify the occlusal relationship and the number of remaining teeth or the use of prosthesis, but these limitations did not compromise the reliability of the results. It is known that a dental prosthesis substantially affects masticatory effectiveness, as demonstrated by Bajoria et al. (26) and Bessadet et al. (27). In the present study, the comparison between groups exhibited statistically significant differences in three domains of the interview, breathing (II), chewing and swallowing (IV), and dryness of the mouth $(\mathrm{Vl})$, as well as in all domains of the clinical examination.

The rationale behind the occurrence of the breathing domain in individuals with CLAP is that palate involvement generally causes the reduction of the nasal airway, leading to mouth breathing. Additionally, in individuals with CLAP, the air passage through the airway and pharynx and the involvement of the soft tissues results in severe insufficiency that impairs breathing and speech, thus compromising orofacial function (28).

The most prevalent domains of the NOT-S examination in the CLAP group were facial expression (III - 75.0\%), face at rest $(\mathrm{I}-66.7 \%)$, speech $(\mathrm{VI}-50.0 \%)$, and masticatory muscle and jaw function (4 - 41.7\%). During the face expression evaluation, the individuals with CLAP had great difficulty whistling and blowing, which were impaired or performed with visible signs of asymmetry. The NOT-S examination in individuals with Parkinson's disease, Prader-Willi syndrome, Treacher Collins syndrome, and oromandibular dystonia revealed the following most frequent domains: face expression (18), oral motor function (20), and face at rest $(21,29)$, respectively.

In the present study, the CLAP group showed more hypernasal speech than the N-CLAP group, with statistically significant differences. These individuals have an approximately $35 \%$ chance of requiring orthognathic surgery (15), which can contribute to velopharyngeal dysfunction. Of note, velopharyngeal dysfunction may also be the result of palatoplasty failure. It is important to highlight that this study did not verify the type of prosthesis worn by the individuals, so it is possible that a palatal prosthesis to aid in velopharyngeal dysfunction could have been used (25) but was not registered and it's one limitation of the present study.

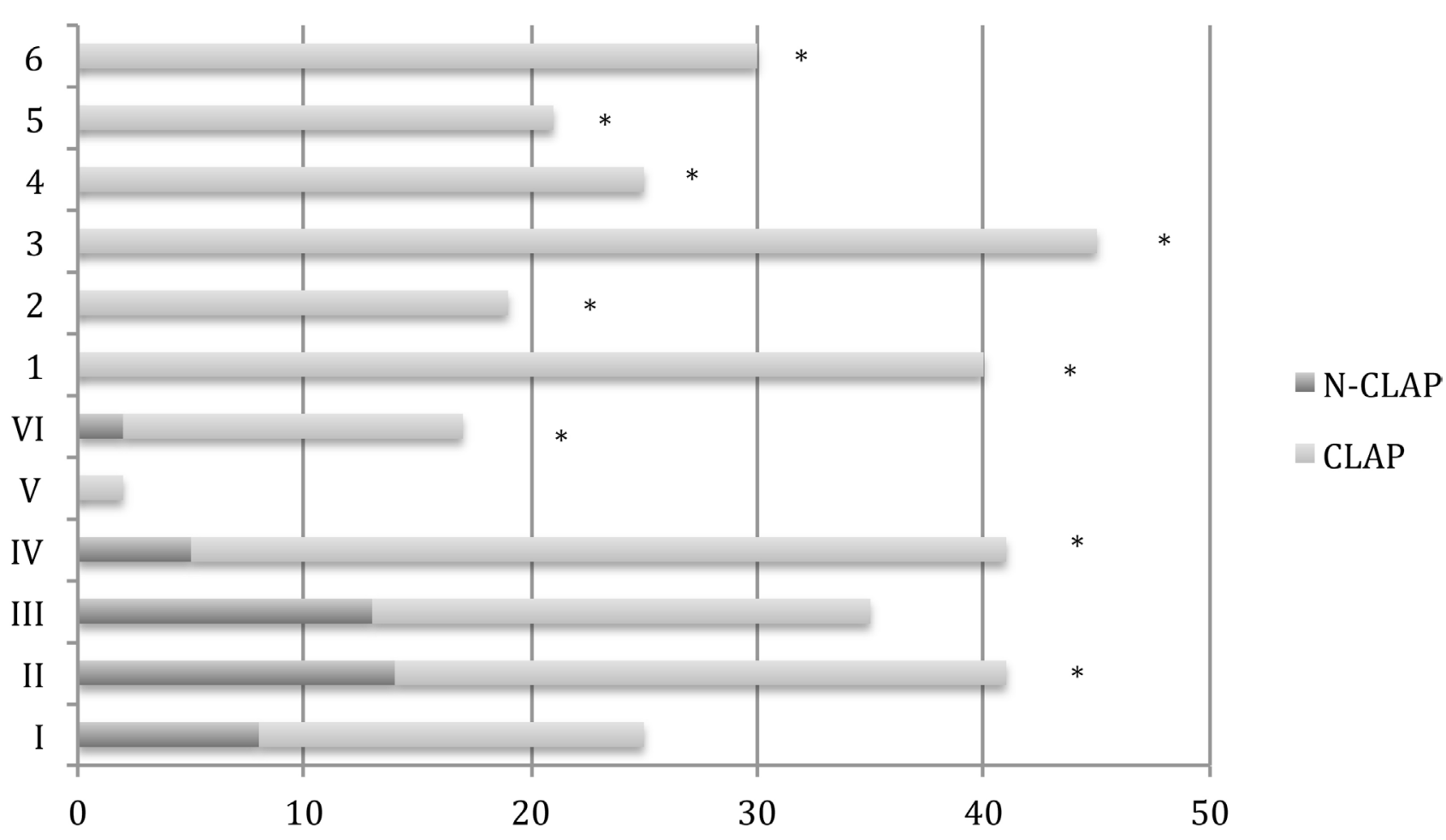

Figure 1. Group differences in NOT-S and presence of oral dysfunction by domain. *Statistically significant difference ( $<<0.05)$. Chi-square test. NOT-S Interview: I. Sensory Function, II. Breathing, III. Habits, IV. Chewing and swallowing, V. Drooling, VI. Dryness of the mouth. NOT-S Examination: 1. Face at rest, 2. Nose breathing, 3. Facial expression, 4. Masticatory muscle and jaw function, 5. Oral motor function, 6. Speech. 
The study conducted by Bakke et al. (1) found that in the individuals with congenital malformation, deformation, and chromosomal abnormality, the most prevalent domains were face at rest and speech (50\% for both domains - 14 individuals). Marked alterations in the face at rest were expected in the individuals with oral clefts because the cleft itself plays a role in visible changes that compromise well-being and social inclusion.

The evaluation showed that individuals with CLAP had more orofacial dysfunction than non-cleft individuals, which corroborates the findings of more orofacial dysfunction in individuals with oral clefts.

The present study agrees with prior results $(1,9,18,19,29)$ that NOT-S is capable of 1 - establishing differences between individuals with orofacial dysfunction and healthy groups and 2 - showing the alterations after treatment. Thus, NOT-S can be used as a standardized instrument to evaluate oral rehabilitation treatment and improve the equivalence of clinical practice and research. The NOT-S assessment verified that the rehabilitation of individuals with oral clefts might give the false impression of correcting the problem when impaired orofacial dysfunction was still present.

CLAP permanently affects the individual, and the early clinical diagnosis of orofacial dysfunction in these individuals enables treatment to minimize the aesthetic and functional damages that are caused by this malformation. From an early age, individuals with CLAP have psychological problems related to speech and aesthetics, which can result in bullying (8) and can greatly affect their lives. During the rehabilitation process, NOT-S can be used to evaluate and follow-up on the treatment, guiding the decision-making process based on the results. We emphasize the need for the involvement of a multidisciplinary team in this process.

The interdisciplinary team must seek excellence in treatment outcomes, from the primary surgeries at early ages to the prosthodontics treatment, focusing on an outcome that can enable the inclusion of the individual with CLAP in society. Future studies should be developed in different specialized treatment centres, using the presented methodology and the results compared. From there, protocols can be established. The priority of the treatments should be focused on the primary plastic surgeries (cheiloplasty and palatoplasty), since as they act contributing to the function and aesthetics; however, primary surgeries cause, over time, deleterious results that prevent maxillary growth in the anteroposterior and transverse direction $(30,31)$.

The NOT-S was able to detect orofacial dysfunction in individuals with and without CLAP, with mean values of 5.00 and 0.63 , respectively. Although CLAP rehabilitative treatment aims at achieving the same aesthetic, physiological, and functional conditions of individuals without CLAP, this study showed that treatment does not meet these expectations. Based on the results of the present study, new protocols and paradigm shifts are needed to obtain a final outcome of CLAP treatment that is similar to that of individuals without clefts.

Individuals with CLAP showed more orofacial dysfunction than non-cleft patients, without gender differences, after being assessed through the NOT-S. This questionnaire should be used to evaluate and follow-up on treatment, as well as to provide new directions for rehabilitative therapy.

\section{Resumo}

A fissura de lábio, alvéolo e palato é uma malformação congênita causada pela falta de fusão dos processos embrionários labial e palatino, que podem comprometer as principais funções do sistema estomatognático. Utilizando o Nordic Orofacial Test - Screening (NOT-S), este estudo transversal observacional, objetivou avaliar a presença da disfunção orofacial nos individuos com fissura de lábio, alvéolo e palato em relação a indivíduos sem fissura ou anomalia craniofacial. Cento e vinte indivíduos entre 32 e 65 anos de idade foram selecionados e divididos em dois grupos: pacientes sem fissura labiopalatina (N-CLAP) e pacientes com fissura de lábio, alvéolo e palato (CLAP). Os dois grupos foram combinados por gênero. Cada indivíduo foi entrevistado e submetido a uma avaliação clínica durante a qual o NOT-S foi utilizado para avaliar a disfunção orofacial. 0 teste de Mann-Whitney comparou desempenho no NOT-S entre os grupos. 0 teste Qui-Square comparou os domínios NOT-S entre os grupos. A concordância intra-examinador foi $K=0,75$. Uma comparação dos escores de NOT-S entre os grupos revelou diferenças estatisticamente significativas no gênero $(p<0,001)$, mas não foram encontradas diferenças estatisticamente significativas na comparação de gênero intragrupo. A avaliação dos domínios de NOT-S entre os grupos $\mathrm{N}$-CLAP e CLAP apresentou diferenças estatisticamente significativas nos domínios II $(p=0,021)$, IV $(p<0,001)$ e VI $(p=0,002)$ da entrevista e diferenças significativas em todos os domínios do exame clínico $(p<0,001)$. Individuos com CLAP apresentaram maior presença de disfunção orofacial do que os individuos sem fissura labioapalatina, conforme avaliado pelo NOT-S.

\section{References}

1. Bakke M, Bergendal B, McAllister A, Sjogreen L, Asten P. Development and evaluation of a comprehensive screening for orofacial dysfunction. Swed Dent J 2007;31:75-84.

2. Mossey PA, Little J, Munger RG, Dixon MJ, Shaw WC. Cleft lip and palate. Lancet 2009;374:1773-1785.

3. Freitas JAS, das Neves $L T$, de Almeida AL, Garib DG, Trindade-Suedam IK, Yaedú RYF, et al. Rehabilitative treatment of cleft lip and palate: experience of the Hospital for Rehabilitation of Craniofacial Anomalies/USP (HRAC-USP) - Part 1: overall aspects. J Appl Oral Sci 2012;20:9-15

4. Castro MSJ, Toro AADC, Sakano E, Ribeiro JD. Evaluation of oral functions of the stomatognathic system according to the levels of asthma severity. J Soc Bras Fonoaudiol 2012;24:119-124.

5. Tunçbilek G, Ozgür F, Belgin E. Audiologic and tympanometric findings in children with cleft lip and palate. Cleft Palate Craniofac J 2003;40:304-309.

6. Kuehn DP, Moller KT. Speech and language issues in the cleft palate population: the state of the art. Cleft Palate Craniofac J 2000;37:348383.

7. Tungotyo M, Atwine D, Nanjebe D, Hodges A, Situma M. The prevalence and factors associated with malnutrition among infants with cleft palate and/or lip at a hospital in Uganda: a cross-sectional study. BMC 
Pediatr 2017;13;17:17.

8. Lorot-Marchand A, Guerreschi P, Pellerin P, Martinot V, Gbaguidi CC, Neiva $C$, et al. Frequency and socio-psychological impact of taunting in school-age patients with cleft lip-palate surgical repair. Int J Pediatr Otorhinolaryngol 2015;79:1041-1048.

9. Bergendal B, Bakke M, McAllister A, Sjögreen L, Åsten P. Profiles of orofacial dysfunction in different diagnostic groups using the Nordic Orofacial Test (NOT-S)-a review. Acta Odontol Scand 2014;72:578-584.

10. Edvinsson SE, Lundqvist LO. Prevalence of orofacial dysfunction in cerebral palsy and its association with gross motor function and manual ability. Dev Med Child Neurol 2016;58:385-394.

11. de Oliveira RL, de Santana Santos T, de Almeida Teixeira JL, MartinsFilho PR, da Silva LC. Health-related quality of life patients with a cleft lip and/or palate. J Craniofac Surg 2015;26:2315-2319.

12. Queiroz Herkrath AP, Herkrath FJ, Rebelo MA, Vettore MV. Measurement of health-related and oral health-related quality of life among individuals with nonsyndromic orofacial clefts: a systematic review and meta-analysis. Cleft Palate Craniofac J 2015;52:157-172.

13. Antonarakis GS, Patel RN, Tompson B. Oral health-related quality of life in non-syndromic cleft lip and/or palate patients: a systematic review. Community Dent Health 2013;30:189-195.

14. Corrêa de Queiroz Herkrath AP, Herkrath FJ, Bessa Rebelo MA Vettore MV. Determinants of health-related and oral health-related quality of life in adults with orofacial clefts: a cross-sectional study. Cleft Palate Craniofac J 2018 Jan 1:1055665618763377. doi: 10.1177/1055665618763377. [Epub ahead of print]

15. Freitas JAS, Garib DG, Trindade-Suedam IK, Carvalho RM, Oliveira TM, Lauris RCMC, et al. Rehabilitative treatment of cleft lip and palate: experience of the Hospital for Rehabilitation of Craniofacial Anomalies - USP (HRAC-USP) - Part 3: oral and maxillofacial surgery. J Appl Oral Sci 2012;20:673-679.

16. Leme MS, Barbosa TS, Gavião MBD. Assessment of orofacial functions in Brazilian children using the Nordic Orofacial Test-Screening (NOT-S). Rev Odonto Cienc 2012;27:108-114.

17. Asten $\mathrm{P}, \mathrm{Akre} \mathrm{H}$, Persson $\mathrm{C}$. Associations between speech features and phenotypic severity in Treacher Collins syndrome. BMC Med Genet 2014;28:15-47.

18. Bakke M, Larsen $S L$, Lautrup $C$, Karlsborg M. Orofacial function and oral health in patients with Parkinson's disease. Eur J Oral Sci 2011;119:2732.

19. Bergendal B, McAllister A, Stecksen-Blicks C. Orofacial dysfunction in ectodermal dysplasias measured using the Nordic Orofacial TestScreening protocol. Acta Odontol Scand 2009;67:377-381.

20. Saeves $R$, Asten $P$, Storhaug $K$, Bagesund M. Orofacial dysfunction in individuals with Prader-Willi syndrome assessed with NOT-S. Acta
Odontol Scand 2011:69:310-315

21. Asten $P$, Skogedal N, Nordgarden $H$, Axelsson $S$, Akre H, Sjögreen L. Orofacial functions and oral health associated with Treacher Collins syndrome. Acta Odontol Scand 2013;71:616-625.

22. Strini PJ, Strini PJ, De Souza Barbosa T, Duarte Gavião MB. Assessment of orofacial dysfunctions, salivary cortisol levels and oral health related quality of life (ORHQoL) in young adults. Arch Oral Biol 2011;56:15211527.

23. Lundeborg I, McAllister A, Graf J, Ericsson E, Hultcrantz E. Oral motor dysfunction in children with adenotonsillar hypertrophy-effects of surgery. Logoped Phoniatr Vocol 2009;34:111-116.

24. Freitas JAS, Garib DG, Oliveira TM, Lauris RCMC, Almeida ALPF, Neves LT, et al. Rehabilitative treatment of cleft lip and palate: experience of the Hospital for Rehabilitation of Craniofacial Anomalies - USP (HRAC-USP) - Part 2: pediatric dentistry and orthodontics. J Appl Oral Sci 2012;20:272-285

25. Freitas JAS, Almeida ALPF, Soares $S$, Neves LT, Garib DG, TrindadeSuedam IK, et al. Rehabilitative treatment of cleft lip and palate: experience of the Hospital for Rehabilitation of Craniofacial Anomalies/USP (HRAC-USP) - Part 4: oral rehabilitation. J Appl Oral Sci 2013;21:284-292.

26. Bajoria AA, Saldanha S, Shenoy VK. Evaluation of satisfaction with masticatory efficiency of new conventional complete dentures in edentulous patients - a survey. Gerodontology 2012;29:231-238.

27. Bessadet M, Nicolas E, Sochart M, Hennequin M, Veyune JL. Impact of removable partial denture prosthesis on chewing efficiency. J Appl Oral Sci 2013;21:392-396.

28. Aras I, Dogan S. Comparative evaluation of the pharyngeal airways and related soft tissues of unilateral and bilateral cleft lip and palate patients with the noncleft individuals. Cleft Palate Craniofac J 2017;54:53-59.

29. Bakke M, Larsen BM, Dalager T, Moller E. Oromandibular dystoniafunctional and clinical characteristics: a report on 21 cases. Oral Surg Oral Med Oral Pathol Oral Radiol 2013;115:21-26.

30. Dadáková M, Cagáková V, Dupej J, Hoffmannová E, Borský J, Veleminská J. Three-dimensional evaluation of facial morphology in pre-school cleft patients following neonatal cheiloplasty. J Craniomaxillofac Surg 2016;44:1109-1116.

31. Bichara LM, Araújo RC, Flores-Mir C, Normando D. Impact of primary palatoplasty on the maxillomandibular sagittal relationship in patients with unilateral cleft lip and palate: a systematic review and metaanalysis. Int J Oral Maxillofac Surg 2015;44:50-56.

Accepted June 25, 2018 Received October 11, 2018 